\title{
ESTRANGEIRIZAÇÃO E DOMESTICAÇÃO NOS QUADRINHOS DE TINTIM
}

\author{
FOREIGNIZING AND DOMESTICATING PRACTICES IN THE COMICS OF \\ TINTIN
}

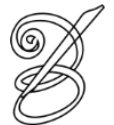 \\ Gabriela Cristina Teixeira Netto do Nascimento ${ }^{1}$ \\ (Mestranda em Estudos da Tradução - POSTRAD/UnB) \\ gabriela.tn@gmail.com
}

\begin{abstract}
Resumo: A tradução de histórias em quadrinhos envolve vários aspectos visuais e verbais. Muitas informações sobre o projeto de tradução podem ser veiculadas por algumas escolhas tanto no texto, como no âmbito dos paratextos descritos por Genette. O presente artigo tem como objeto de análise as traduções do livro Les aventures de Tintin: le lotus bleu, de Hergé para o inglês e o português, levando em consideração os aspectos de estrangeirização e domesticação de Venuti e Berman.
\end{abstract}

Palavras-chave: HQs, paratextos, estrangeirização, domesticação, estudos da tradução.

Abstract: Translation of comics involves many visual and verbal aspects. Several pieces of information regarding the translation project adopted can be transmited due to word choices in the text, as well as other features that can be conveyed through paratexts as described by Genette. In this article, the analysis of the translations into English and Portuguese of Les Aventures de Tintin: Le Lotus Bleu, by Hergé will take place in regards to foreignizing and domesticating practices according to Venuti and Berman.

Key-words: Comics, paratexts, foreignizing, domesticating, translation studies.

\section{Introdução}

s histórias em quadrinhos são textos multimodais, pois combinam mais de uma
forma de expressão. São frequentemente associadas ou comparadas com o âmbito
cinematográfico, uma vez que a narrativa é feita por meio de cenas inseridas em quadros sequenciais. Para Eisner (2012, p.41),

O espectador de um filme não tem como ver o quadro seguinte sem que o criador o permita, porque esses quadros, impressos nos fotogramas, são exibidos um por vez. Assim, o filme, que é uma extensão das tiras de quadrinhos, tem absoluto controle sobre sua leitura - vantagem de que o teatro também desfruta.

No entanto, diferentemente do cinema, os quadros são estáticos, mas acontecem em sequência de acordo com a história a ser contada. Por veicularem informações verbovisuais em quadros, ou frames, as HQs combinam dois aspectos em um, convergindo em uma leitura de um texto que se funde com informações visuais e textuais. 
Assim como outros tipos de texto, as HQs apresentam suas próprias peculiaridades quando se trata de traduzi-las. O tradutor de HQs não pode manipular somente o código verbal. É necessário adequar às estratégias de tradução adotadas de acordo com as limitações impostas pelo código visual. Além disso, há informações culturais e históricas que são transmitidas por meio dos desenhos, bem como por meio de texto. $\mathrm{O}$ tradutor tem que estar atento a essas informações para que os quadrinhos sejam compreendidos individualmente e também como um todo.

De acordo com a relação de língua e literatura de um país, o status da língua para qual o texto será traduzido, assim como a época em que uma HQ é traduzida, vários aspectos de estrangeirização ou domesticação podem ser identificados, como por exemplo, intervenções e deformações bermanianas no texto da língua de chegada. Porém, os paratextos podem servir de apoio para identificar se na obra a estrangeirização ou a domesticação é predominante.

Os aspectos de estrangeirização e domesticação presentes nas traduções para o inglês e para o português do livro Le lotus bleu, são analisados neste artigo, levando-se em consideração os aspectos linguísticos e culturais, bem como informações contidas nos 78 paratextos.

\section{O mundo dos quadrinhos}

As histórias em quadrinhos foram deixadas de lado por muitos anos, ignoradas por serem tratadas como uma forma inferior de narrativa. Porém, de acordo com Hudinilson Urbano, responsável pelo prefácio de Faces do humor: uma aproximação entre piadas e tiras, de Paulo Ramos, apesar de serem "vistas como simples leitura de entretenimento e muitas vezes de forma pejorativa e preconceituosa pelos intelectuais e academia, [...] enraizaram-se, floresceram e efervesceram no seio do povo".

O mundo dos quadrinhos já não é mais frequentemente associado com o universo infanto-juvenil. É possível inserir HQs em sala de aula, em provas de vestibulares e até há estímulo do governo para que os professores usem os quadrinhos no ensino (RAMOS a., 2012, p.13).

As histórias em quadrinhos abarcam diversas formas de expressão por meio de imagens e texto. Algumas delas são: tiras (cômicas, livres, seriadas, de aventura), charges, cartuns e romances gráficos (graphic novel). O formato das histórias em quadrinhos é uma das maneiras mais fáceis de identificar esse tipo de texto. $\mathrm{O}$ texto é composto por informações 
textuais e visuais em quadros, sendo que cada quadro representa uma vinheta que, assim como no cinema, tem a função de mostrar uma parte da história a ser narrada.

No âmbito dos quadrinhos, para Rosa (2010, p.417), “a linguagem pode se unir à imagem, alternando com ela funções de dominância e complementaridade”. É possível ver em diversas histórias a alternância, em alguns momentos o foco é o texto, em outros a imagem. Além disso, Rosa (2010, p.418) afirma que

na tradução de histórias em quadrinhos, sendo o texto parte da própria imagem, fazse necessário que outros fatores sejam levados em consideração na leitura e apreensão de significado pelo tradutor, tais como forma e tamanho dos balões, que trazem significados próprios.

Outras informações extralinguísticas podem ser extraídas a partir do texto. O uso de onomatopeias, marcações de hesitações, tamanho e tipo de fonte, bem como se o autor usa caixa alta para transmitir uma mensagem, se a fala é apresentada em negrito, itálico ou em outra cor. O tamanho e tipo dos balões de fala também trazem outras informações, por exemplo, eles podem ser apresentados de forma redonda, quadrada, retangular, ou somente com um apêndice, em formato de nuvem ou bolha, escolhas que influenciam no nível textual e imagético da narrativa. Pois revelam que tipo de discurso está sendo veiculado. O uso de balão de fala em formato de nuvem pode indicar que a fala é interior ou que se trata de um sonho ou imaginação, por outro lado, balões de fala com linhas sinuosas podem indicar que a fala é direta e o tom - de raiva - do discurso.

Além disso, os espaços entre os quadros, mais conhecidos no âmbito dos quadrinhos como sarjetas, são preenchidos pelas experiências e informações prévias de cada leitor transformando "duas imagens distintas e as transforma em uma única ideia" (MCCLOUD, 2004, p.66). A soma das imagens com as falas torna o texto completo, de forma que o leitor tem que estar atento aos elementos verbovisuais no "mecanismo de leitura para a construção de sentido" (RAMOS b., 2012, p.750).

\section{A tradução de HQs}

A tradução de quadrinhos não pode ser focada somente no texto, uma vez que as informações visuais fazem parte da narrativa. O tradutor não pode menosprezar o texto em função da imagem, nem a imagem por causa do texto, uma vez que a leitura de quadrinhos é realizada a partir da junção das informações textuais e visuais. 
Os signos presentes em textos com informações verbovisuais tendem a aparecer em um dos sistemas ou nos dois. A visualização da metáfora ou do símile pode ocorrer no plano do discurso escrito, bem como na visualização da imagem. Por exemplo, se um personagem tem uma ideia, ele pode expressar dizendo: “Tive uma ideia!”, o que comumente acontece no âmbito de quadrinhos é a concretização dessa oração na forma visível por meio de uma lâmpada piscando acima da cabeça do personagem, ou se estiver passando mal sentir a cabeça rodando (com auxílio de linhas cinéticas), se houver algum encontro amoroso, corações suspensos no ar, etc (ECO, 1979, p.144).

O signo verbal pode representar um objeto para o intérprete de uma cultura e outro objeto diferente para outro intérprete. Por exemplo, a palavra pão para o público brasileiro em um primeiro momento remete a imagem de pão francês, já bread para o público inglês e americano a visualização de pão não é a mesma, a imagem visual será de pão de forma inteiro ou fatiado, para os franceses será a baguette. Deve-se prestar atenção a esses fatores e detalhes, pois eles podem ser vinculados diretamente à imagem, provocando um desafio ao tradutor. De acordo com Santaella (2005, p.45):

O signo é múltiplo, variável e modifica-se de acordo com o olhar do observador [...] mas é preciso lembrar que o signo tem uma autonomia relativa em relação ao seu intérprete. Este apenas atualiza alguns níveis de um poder que já está no signo.

Em uma determinada cena da página 25, um dos vilões corre atrás de Tintim com uma adaga. Em português a tradução é "punhal" e em inglês é "knife" (= faca). Entretanto, a imagem visual é de um punhal de brinquedo, que não corta e não é firme como um de verdade. Em inglês o signo verbal é "latão", enquanto que em inglês é "rubber" (= borracha).

\section{Os paratextos nas traduções de Le lotus bleu}

Ao se analisar uma obra é importante analisar os paratextos dela. Os enunciados que envolvem um texto, como o título, os subtítulos, a capa, a contracapa, as abas ou orelhas, informações visuais como as ilustrações e desenhos gráficos e tipográficos e o formato da obra são conhecidos como paratextos.

Um elemento de um paratexto consiste em uma mensagem materializada. Essa mensagem está relacionada com o texto, como o título ou o prefácio. Além disso, pode estar inserida em pequenas partes do texto, como nos "títulos de capítulos e notas" (GENETTE; MACLEAN, 1991, p.264). 
Os elementos paratextuais podem ser significativos quando se pensa no papel do tradutor. Segundo Ferreira de Freitas e Araújo da Silva (2012, p.240), nos paratextos também "o tradutor pode ter voz e visibilidade". Informações como uma introdução feita pelo tradutor, quando a obra foi traduzida, o nome do tradutor, se há prefácio ou posfácio do tradutor, bem como notas tradutórias são indicadores em que o tradutor é colocado em destaque.

As traduções da HQ Le lotus bleu para o inglês e português mostram algumas discrepâncias no que tange o âmbito dos paratextos. Para evidenciar as diferenças entre os paratextos das publicações em questão, duas tabelas foram elaboradas.

Tabela 1. Capa

\begin{tabular}{|c|c|c|c|}
\hline Título & Autor & Menção do tradutor & Editora \\
\hline O lótus azul & Hergé & Não & Quadrinhos na Cia. \\
\hline The blue lotus & Hergé & Não & - \\
\hline
\end{tabular}

Fonte: Elaborada pela autora

Tabela 2. Páginas internas

\begin{tabular}{|c|c|c|c|c|c|}
\hline $\begin{array}{c}\text { Data de } \\
\text { publicação }\end{array}$ & Título & $\begin{array}{c}\text { Menção do } \\
\text { tradutor }\end{array}$ & Coleção & $\begin{array}{c}\text { Menção } \\
\text { língua/cultura de } \\
\text { origem }\end{array}$ & $\begin{array}{c}\text { Data de } \\
\text { tradução }\end{array}$ \\
\hline 2005 & $\begin{array}{c}\text { O lótus } \\
\text { azul }\end{array}$ & $\begin{array}{c}\text { Tradução de } \\
\text { Eduardo } \\
\text { Brandão }\end{array}$ & $\begin{array}{c}\text { As aventuras de } \\
\text { Tintim }\end{array}$ & $\begin{array}{c}\text { Título original: Le } \\
\text { lotus bleu (les } \\
\text { aventures de } \\
\text { Tintin) }\end{array}$ & 2005 \\
\hline 2011 & $\begin{array}{c}\text { The blue } \\
\text { lotus }\end{array}$ & Não & $\begin{array}{c}\text { The adventures } \\
\text { of Tintin }\end{array}$ & Não & $1983(?)$ \\
\hline
\end{tabular}

Fonte: Elaborada pela autora

Outras informações presentes nos paratextos das publicações traduzidas são as diferenças acerca da ilustração da capa, bem como da contracapa; o tamanho do álbum em português é do mesmo do álbum em francês $(20 \mathrm{~cm}$ x $15 \mathrm{~cm})$, já o álbum em inglês é menor $(15 \mathrm{~cm} \times 10 \mathrm{~cm})$.

A maior diferença entre as duas traduções é que no livro em português o leitor sabe que se trata de uma tradução, no livro em inglês não há menção de que seja uma tradução. Consta na segunda página de The lotus blue que se trata de um álbum original. O nome do 
álbum não aparece em francês e sim em inglês. Não há referências ao lugar onde a edição da língua de partida foi publicada, muito menos que o livro se trata de uma tradução. O tradutor não é mencionado. Apenas há a indicação dos direitos sobre o texto, que são da editora Egmont UK Limited, de 1983, porém, não se sabe se a tradução para o inglês é da mesma data que os direitos sobre o texto.

As indicações verbais, numéricas e iconográficas que aparecem na capa, como o nome ou pseudônimo do autor, o título da obra, emblema da coleção, preço de venda e nome da editora acrescentam indicações "mais globais relativas ao estilo ou ao desenho da capa, característico do editor, da coleção, ou de um grupo de coleções” (GENETTE, 2013, p.28). As diferenças entre as publicações em inglês e português aparecem também na capa. Ambas são vermelhas com o pseudônimo do autor na parte superior em tamanho pequeno, depois aparece o título da coleção As aventuras de Tintin e The adventures of Tintin, e embaixo em destaque se tem o título da obra em tamanho visivelmente maior. A ilustração da tradução para língua portuguesa é a mesma do original em francês e com a disposição do nome da editora na parte inferior seguindo o mesmo padrão. O álbum em inglês tem outra ilustração e

82 não há o nome da editora - Little, Brown and Company - na capa.

Os paratextos são importantes na leitura completa de uma obra, pois podem ajudar o leitor a compreender as intenções iniciais do autor, ou do editor, o objetivo de uma determinada publicação ser veiculada com tantos, ou poucos, elementos paratextuais. As diferenças entre as duas publicações indicam públicos e projetos de tradução diferentes. A tradução do livro para os EUA, em formato pocket, não traz o nome do tradutor, levando o leitor a pensar que o livro foi escrito originalmente em inglês, diferentemente da publicação da tradução para o Brasil que adota a linha da publicação do livro em francês e insere informações sobre o processo editorial, colocando os passos de tradução, revisão, preparação, composição e atualização ortográfica em destaque. Essas informações paratextuais sugerem que o público brasileiro é mais receptivo à prática estrangeirizadora, enquanto o público americano prefere uma abordagem domesticadora.

\section{Estrangeirização x Domesticação}

Um dos conceitos introduzido por Venuti (1996) é o de domesticação na tradução. A definição de dessa prática implica na 
supressão das diferenças linguísticas e culturais do texto estrangeiro, assimilando-o aos valores dominantes na cultura da língua-alvo, tornando-o reconhecível e, dessa forma, aparentemente não traduzido. Com essa domesticação o texto traduzido passa por original, uma expressão da intenção do autor estrangeiro (VENUTI, 1996, p.111).

Ao fazer uso de estratégias domesticadoras, o tradutor deve estar ciente que uma escolha mais radical, por exemplo, a de traduzir um provérbio na língua de partida por um equivalente dinâmico na língua de chegada pode produzir uma incoerência, devido ao fato de que muitas vezes essas informações linguísticas são representadas na imagem. Por mais que no nível textual a leitura seja fluida e simples, a leitura visual provocará desconforto no leitor por causa da diferença de sentido.

No entanto, se o tradutor compreender a noção de equivalência do ponto de vista de Berman (2013, p.20), "a formulação diferente da mesma sabedoria”, pode-se alcançar uma "tradução da forma-provérbio", na qual se pode forçar a língua de chegada e modificar alguns elementos da língua de partida. Uma abordagem do tipo "tradução formaprovérbio" leva em consideração "o ritmo, o comprimento (ou concisão) do provérbio, eventuais aliterações" etc. Ao procurar provérbios que se encaixem na visão de equivalência dinâmica de $\mathrm{Nida}^{2}$, não se limita a procura de somente um sentido invariável entre o par de línguas em uma tradução. Essa noção implica na recusa de introduzir elementos que causem estranheza nos provérbios, significa "recusar fazer da língua para a qual se traduz 'o albergue do longínquo', significa, para nós, afrancesar: velha tradição" (idem, p.22).

Uma tradução fluente implica na invisibilidade do tradutor, e essa invisibilidade também é, em parte, determinada pela concepção individualista de autoria presente na cultura Anglo-Americana. Para se alcançar uma tradução estrangeirizadora é necessário incorporar valores textuais que estão à margem na cultura meta, deixar em segundo plano o cânone local, ou seja, ir contra a corrente desafiando o cânone estabelecido e introduzir discursos que não têm muito espaço em um determinado campo literário, como discursos da periferia e gêneros e estilos que não são comuns na cultura alvo.

Para Venuti (1996, p.17), a invisibilidade do tradutor pode ter proporções preocupantes, uma vez que o discurso transparente por meio da domesticação de textos estrangeiros, principalmente em língua inglesa, seleciona que textos são passíveis de ter tradução fluente, e também porque a invisibilidade apaga o trabalho da tradução. 


\section{Análise das traduções $O$ lótus azul e The blue lotus}

A partir das reflexões feitas sobre o universo dos quadrinhos, a tradução de HQs, as diferenças entre os paratextos nas duas publicações e a as práticas de estrangeirização e domesticação na tradução, alguns exemplos das duas traduções serão dados.

A primeira diferença observada entre as traduções e o original é a introdução, semelhante a uma página de jornal, que reconta algumas aventuras de Tintim e onde ele está. As diferenças podem ser vistas nas figuras abaixo.

Figura 1. Introdução - original - Le lotus bleu

\begin{tabular}{|c|c|}
\hline DES NOUVEL & ES DE TINTIN \\
\hline $\begin{array}{l}\text { On se souvient de la } \\
\text { lutte sans merci que le } \\
\text { jeune reporter Tintin } \\
\text { avait engagée contre une } \\
\text { puissante bande interna- } \\
\text { tionale de trafiquants de } \\
\text { stupéfiants. } \\
\text { Nos lecteurs n'ont } \\
\text { certes pas oublié que le } \\
\text { jeune globe-trotter avait } \\
\text { réussi, après de multi- } \\
\text { ples aventures, à faire } \\
\text { mettre sous les verrous } \\
\text { les principaux affiliés de } \\
\text { la bande, à l'exception } \\
\text { de leur chef qui, à la } \\
\text { suite d'une chute dans }\end{array}$ & $\begin{array}{l}\text { un précipice, avait trouvé } \\
\text { la mort. } \\
\text { Rappelons à cet effet } \\
\text { que ce personnage } \\
\text { mystérieux n'a jamais pu } \\
\text { être identifié et que son } \\
\text { corps, d'ailleurs, n'a ja- } \\
\text { mais été retrouvé. } \\
\text { Nous apprenons au- } \\
\text { jourd'hui que le sym- } \\
\text { pathique reporter et son } \\
\text { inséparable Milou sont } \\
\text { toujours les hôtes du } \\
\text { Maharadjah de Rawhaj- } \\
\text { poutalah, chez qui ils } \\
\text { goûtent un repos bien } \\
\text { mérité. }\end{array}$ \\
\hline
\end{tabular}

Fonte: Le lotus bleu, Casterman, p.1

Figura 2. Introdução - português - O lótus azul

\begin{tabular}{|c|c|}
\hline NOTÍC & DE TINTIM \\
\hline $\begin{array}{l}\text { Vocês devem se lem- } \\
\text { brar da luta implacável } \\
\text { que o jovem repórter Tin- } \\
\text { tim travou contra uma po- } \\
\text { derosa quadrilha interna- } \\
\text { cional de traficantes de } \\
\text { drogas. } \\
\text { Vocês certamente não } \\
\text { esqueceram que o nosso } \\
\text { jovem viajante, depois de } \\
\text { muitas aventuras, con- } \\
\text { seguiu botar na cadeia } \\
\text { os principais membros da } \\
\text { quadrilha, com exceção }\end{array}$ & $\begin{array}{l}\text { do chefe, que despencou } \\
\text { num precipício e morreu. } \\
\text { É bom lembrar que nin- } \\
\text { guém jamais conseguiu } \\
\text { identificar esse misterio- } \\
\text { so personagem, e que seu } \\
\text { corpo nunca foi encontrado. } \\
\text { Soubemos hoje que o } \\
\text { simpático repórter e seu in- } \\
\text { separável Milu continuam } \\
\text { hóspedes do marajá de } \\
\text { Rawhajpurtalah, em cujo } \\
\text { palácio gozam de um me- } \\
\text { recido repouso. }\end{array}$ \\
\hline
\end{tabular}

Fonte: O lótus azul, Quadrinhos na Cia, p.1 
Figura 3. Introdução - inglês - The blue lotus

\begin{tabular}{|c|c|}
\hline $\begin{array}{l}\text { TINTIN AND SNOWY are } \\
\text { in India, guests of the } \\
\text { Maharaja of Gaipajama, } \\
\text { enjoying a well-earned } \\
\text { rest. The evil gang of } \\
\text { international drug smugglers, } \\
\text { encountered in Cigars of } \\
\text { the Pharaoh, has been } \\
\text { smashed and its members } \\
\text { are behind bars. With } \\
\text { one exception. Only the } \\
\text { mysterious gang-leader }\end{array}$ & $\begin{array}{l}\text { is unaccounted for: he } \\
\text { disappeared over a cliff. } \\
\text { But questions have still } \\
\text { to be answered. What of } \\
\text { the terrible Rajaijah juice, } \\
\text { the poison of madness'? } \\
\text { Where were the shipments of } \\
\text { opium going, hidden in the } \\
\text { false cigars? And who really } \\
\text { was the master-mind behind } \\
\text { the operation? }\end{array}$ \\
\hline
\end{tabular}

Fonte: The blue lotus, Little, Brown and Company, p.1

As diferenças entre as introduções se iniciam na apresentação. A tradução em português segue a mesma diagramação e formatação da introdução do original, assim como o tamanho e tipo de fonte escolhida. Optou-se por uma tradução literal, inclusive no sentido bermaniano da letra, uma vez que a confluência da representação de signos gráficos, que não causa estranhamento ao leitor.

$\mathrm{Na}$ introdução da versão em inglês, omite-se DES NOUVELLES DE TINTIN e se inicia de modo impessoal, o que não ocorre na tradução em português que usa "vocês" nos dois primeiros parágrafos, estabelecendo assim um diálogo com o leitor.

Ocorre o processo de aclimatação dos nomes dos personagens para o português. $\mathrm{O}$ nome do personagem principal "Tintin" passa a ser "Tintim" e o de "Milou" passa a ser "Milu", adaptando os nomes estrangeiros "à fonologia" e/ou "à estrutura morfológica da língua que o importa" (BARBOSA, 2004, p.73). Manteve-se o nome "Tintin" em inglês, mas o nome do fiel companheiro foi traduzido como "Snowy", por ser um nome comum para cachorros pequenos e brancos. Entretanto, perde-se uma referência afetiva importante, pois o nome foi inspirado na namorada de Hergé, Marie-Louise Von Custen que era chamada de "Malou"3.

O nome do marajá, "Rawhajpurtalah", é alterado para "Gaipajama" no texto em inglês. Trata-se da adaptação do nome próprio do personagem. Entretanto, não se sabe o motivo que levou a adaptação desse nome específico, visto que os outros nomes de personagens estrangeiros não foram alterados na trama.

Além disso, insere-se a informação de que a quadrilha de traficantes estava presente no livro anterior. A frase que indica que o chefe despencou de um precipício e morreu, 
presente nos textos em francês e português, é reformulada no texto em inglês que diz que ele pulou de um penhasco e desapareceu. O efeito dessa reformulação se dá em um texto com algumas das tendências deformadoras de Berman, sendo as principais a racionalização "linearização das arborescências sintáticas" e a clarificação que "visa a tornar algo claro o que não é e não quer ser no original" (BERMAN, 2012, p.70).

O último parágrafo do texto em inglês não aparece no texto original, nem no texto traduzido para o português. Ele revela para o leitor que não conhece a história anterior que Tintim vai enfrentar algumas aventuras acerca do veneno da loucura, os carregamentos de ópio e quem é o mandante por trás da operação lótus azul, informações que aparecem no livro anterior. A explicitação da intertextualidade com outras obras de Hergé está presente na edição em inglês por se tratar de um público alvo infanto-juvenil ${ }^{4}$.

As interjeições e as onomatopeias ao longo das traduções foram realizadas de forma que o leitor possa identificar os sons representados na língua de chegada (figura 4).

Figura 4. Interjeição - faquir (francês, português e inglês)

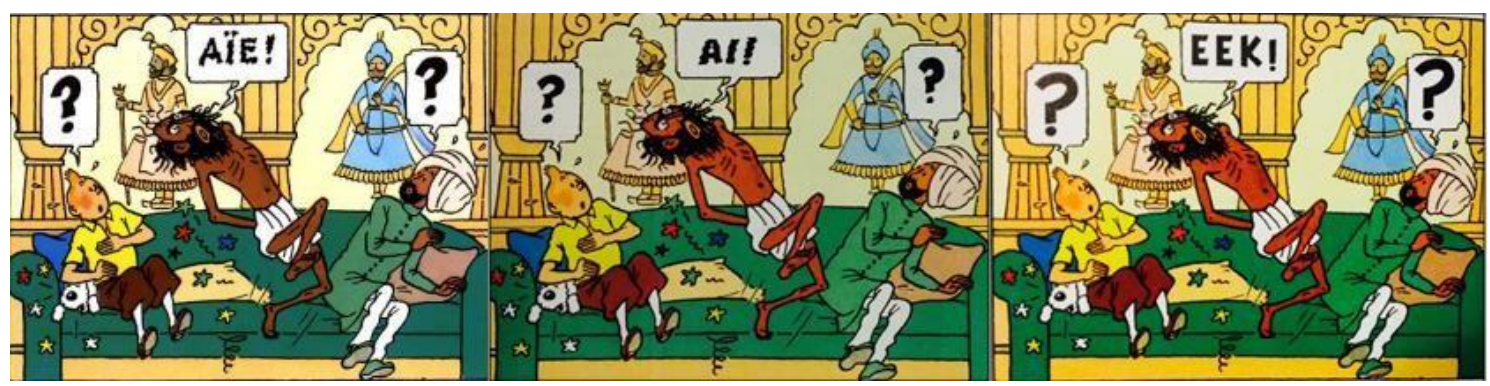

Fonte: Compilação dos quadros de Le lotus bleu, O lótus azul, The blue lotus, p.2

Optou-se em ambas as traduções pela interjeição correspondente na língua de chegada. Em histórias em quadrinhos não há uma regularidade sobre o uso de onomatopeias. Muitas são decalques do inglês, outras são formas de representação de sons conforme os roteiristas querem transmitir a sensação para o leitor. Algumas das onomatopeias em português são "au au", "bum" e "pluf" e as correspondentes em inglês são "wooah wooah", "boom" e "sposh".

No português há diversas frases longas que não priorizam a oralidade fingida oralidade construída no discurso escrito por um ficcionista, a fim de proporcionar ao leitor uma leitura ilusória de "uma representação fiel da linguagem falada na escrita" (BRAGA, 2013, p.17).

O propósito dela não é reproduzir a oralidade real, como uma transcrição, mas sim simulá-la nos diálogos por meio de estratégias textuais inerentes de cada autor (SERRA e 
DEUS, 2012, p. 36). Trata-se de recriar um discurso oral no universo do texto literário para que o leitor disfrute da sensação de ouvir aos personagens enquanto lê. Essa representação da fala oral espontânea no discurso escrito permite com que os diálogos sejam lidos e aceitos “com naturalidade, no gênero quadrinhos, pelos leitores” (BRAGA, 2013, p.2).

Por outro lado, há a omissão dos pronomes pessoais do caso reto, e as escolhas lexicais podem indicar ao leitor que As aventuras de Tintim não foram escritas recentemente, apesar de a publicação de $O$ lótus azul ser de 2005. Por exemplo, "Carambola, estou congelando" (HERGÉ, 2005, p.21). Há a omissão do pronome "eu" antes de estou e a escolha lexical para indicar surpresa de algo incomum - "carambola", leva o leitor a pensar em quando que esse texto foi escrito, pois não é comum usar esse tipo de vocabulário atualmente.

Para alcançar a ilusão de uma fala ficcional no discurso escrito é necessário priorizar diálogos coloquiais, mas vários diálogos na obra em questão foram traduzidos priorizando a norma culta ou padrão, causando estranhamento ao público por serem inverossímeis. Britto (2012, p.87) afirma que o tradutor precisa "identificar certas marcas textuais que criem esse efeito de verossimilhança, essa impressão de que estamos lendo a fala de uma pessoa".

O personagem japonês Mushirato, bem como o chinês Chen, usam frequentemente pronomes oblíquos e a ênclise ao invés da próclise, projetando a sensação de que não se trata de um discurso oral. Alguns exemplos são: “[...] Ninguém $o$ viu entrar e ninguém $o$ verá sair, se for essa a minha vontade...” (HERGÉ, 2005, p.23, marcação minha), “[...] Em vez disso, resolvi que vou libertá-lo..." (idem, marcação nossa). Por ser mais rebuscada, comparada com a de outros personagens, o estilo de fala pode indicar a posição econômica e social deles.

Britto (2012, p.83) ressalta que "na vida real, falamos por frases incompletas, com uma sintaxe totalmente fraturada, com redundâncias e lacunas”. Os diálogos em inglês têm várias orações curtas, uso frequente de reticências para indicar hesitação, bem como o uso de contrações para dar o efeito oral a um texto escrito, como na conversa entre dois personagens que querem destruir os trilhos de trem: "You have everything?" - omissão de Do no início da pergunta e mostra uma sintaxe incompleta; "Someone over there!...Look!...A spy!..." - três orações curtas e diretas separadas por exclamações e reticências, indicando uma fala fragmentada (HERGÉ, 2011, p.21).

Para outros exemplos constando as três publicações, observe a tabela 3. 
Tabela 3. Trechos de traduções

\begin{tabular}{|c|c|c|c|}
\hline Página & Francês & Português & Inglês \\
\hline 7 & $\begin{array}{l}\text { "Votre conduite est } \\
\text { indigne d'un } \\
\text { gentleman, } \\
\text { Monsieur!" } \\
\text { (Cinco linhas, } 54 \\
\text { caracteres com } \\
\text { espaço) }\end{array}$ & $\begin{array}{l}\text { "Sua conduta é indigna de } \\
\text { um cavalheiro, senhor!" } \\
\text { (Quatro linhas, } 49 \text { caracteres } \\
\text { com espaço) }\end{array}$ & $\begin{array}{l}\text { "Your conduct is } \\
\text { disgraceful, sir!" } \\
\text { (Três linhas, } 35 \\
\text { caracteres com espaço) }\end{array}$ \\
\hline \multicolumn{2}{|r|}{$F$} & $\begin{array}{l}\text { - Tradução literal, } \\
\text { - A palavra gentleman foi } \\
\text { traduzida pela forma } \\
\text { correspondente }\end{array}$ & $\begin{array}{l}\text { - Texto mais } \\
\text { domesticado, } \\
\text { - Há omissão de } \\
\text { gentleman }\end{array}$ \\
\hline 12 & $\begin{array}{l}\text { "Empoisonné? Non, } \\
\text { Dieu soit loué! Son } \\
\text { coeur bat encore... Il } \\
\text { dort... Aurait-il } \\
\text { absorbé un } \\
\text { narcotique?" } \\
\text { (Cinco linhas, } 102 \\
\text { caracteres com } \\
\text { espaço) }\end{array}$ & $\begin{array}{l}\text { “Envenenado? Não, graças } \\
\text { a Deus! O coração ainda } \\
\text { bate... Está dormindo... Será } \\
\text { que era um narcótico?” } \\
\text { (Quatro linhas, } 99 \text { caracteres } \\
\text { com espaço) }\end{array}$ & $\begin{array}{l}\text { "Poisoned?... No, thank } \\
\text { goodness! His heart's } \\
\text { still beating... He's } \\
\text { asleep... Drugged?” } \\
\text { (Quatro linhas, } 85 \\
\text { caracteres com espaço) }\end{array}$ \\
\hline & Análise II & $\begin{array}{l}\text { - Tradução literal, } \\
\text { - Omissão de seu em “O } \\
\text { [seu] coração" e de ele em } \\
\text { "[Ele] Está dormindo...” }\end{array}$ & $\begin{array}{l}\text { - Linguagem direta, } \\
\text { - Poucos verbos } \\
\text { declarativos, } \\
\text { - Discurso direto } \\
\text { - Marca de oralidade } \\
\text { por meio da contração } \\
\text { de is em "heart's" e } \\
\text { "He's", } \\
\text { - Inserção de mais uma } \\
\text { marcação de reticências }\end{array}$ \\
\hline & $\begin{array}{l}\text { "Commandant, je suis } \\
\text { sujet japonais!...j’ai } \\
\text { failli }\end{array}$ & $\begin{array}{c}\text { “Comandante, sou cidadão } \\
\text { japonês... }\end{array}$ & $\begin{array}{l}\text { "Major, I'm Japanese... } \\
\text { I've been half }\end{array}$ \\
\hline
\end{tabular}




\begin{tabular}{|c|c|c|c|}
\hline 25 & $\begin{array}{l}\text { être assassiné par un } \\
\text { jeune Européen...un } \\
\text { espion au service des } \\
\text { Chinois... Il se } \\
\text { nomme Tintin!" } \\
\text { (Cinco linhas, } 142 \\
\text { caracteres com } \\
\text { espaço) }\end{array}$ & $\begin{array}{l}\text { Quase fui assassinado por } \\
\text { um jovem europeu, um } \\
\text { espião a serviço dos } \\
\text { chineses. O nome dele é } \\
\text { Tintim". } \\
\text { (Quatro linhas, } 133 \\
\text { caracteres com espaço) }\end{array}$ & $\begin{array}{l}\text { murdered by a young } \\
\text { European, a Chinese } \\
\text { spy! His name is } \\
\text { Tintin!" } \\
\text { (Quatro linhas, } 102 \\
\text { caracteres com } \\
\text { espaço) }\end{array}$ \\
\hline & Análise III & $\begin{array}{l}\text { - Tradução literal; } \\
\text { - Omissão do pronome } \\
\text { sujeito eu em “[Eu] sou } \\
\text { cidadão" e "[Eu] quase fui”" }\end{array}$ & $\begin{array}{l}\text { - Restruturação dos } \\
\text { períodos, mais curtos e } \\
\text { sucintos; } \\
\text { - Omissão de citizen no } \\
\text { primeiro período; } \\
\text { - Contração de am em } \\
\text { "I'm" e de have em } \\
\text { "I've" }\end{array}$ \\
\hline 33 & $\begin{array}{l}\text { "Je...je suis bien } \\
\text { content } \\
\text { d'eavoir gagné la } \\
\text { course...et...et...j'essa } \\
\text { yerais de faire meiux } \\
\text { prochaine fois." } \\
\text { (Três linhas, } 109 \\
\text { caracteres com } \\
\text { espaço) }\end{array}$ & $\begin{array}{l}\text { "Estou muito feliz por ter } \\
\text { vencido a corrida... e } \\
\text { prometo um resultado } \\
\text { melhor da próxima vez..." } \\
\text { (Três linhas, } 98 \text { caracteres } \\
\text { com espaço) }\end{array}$ & $\begin{array}{l}\text { “I...I'm very happy to } \\
\text { have won...and...and } \\
\text { I'll try to do better next } \\
\text { time...” } \\
\text { (Três linhas, } 78 \\
\text { caracteres com espaço) }\end{array}$ \\
\hline & Análise IV & $\begin{array}{l}\text { - Omissão do pronome eu } \\
\text { no início do período, } \\
\text { - Exclusão de duas marcas } \\
\text { de hesitação por meio de } \\
\text { reticências }\end{array}$ & $\begin{array}{l}\text { - Omissão de run no } \\
\text { primeiro período, } \\
\text { - Contração de am em } \\
\text { "I'm" e de will em "I'll", } \\
\text { - Deslocamento das } \\
\text { reticências para o final } \\
\text { da fala }\end{array}$ \\
\hline
\end{tabular}


A opção por inverter frases ou reduzi-las pode ter ocorrido devido ao tamanho da edição em língua inglesa, o formato é menor que o original. Entretanto, notou-se que o tamanho e tipo de fonte usada eram diferentes. O tipo de fonte é diferente do tipo usado em português e o tamanho também é reduzido. Então, como evidenciado na tabela acima, a escolha de adotar frases curtas, por meio da homogeneização, unifica os tecidos do texto em inglês, "embora este seja originalmente heterogêneo" (BERMAN, 2012, p.77).

\section{Considerações finais}

Uma obra não se limita somente ao texto. Os elementos paratextuais são fonte de informações acerca do projeto de tradução, bem como o papel do tradutor é visto em um determinado sistema de língua-cultura.

A invisibilidade do tradutor depende de como um determinado sistema linguísticocultural compreende o local da diferença e a alteridade. A diferença entre duas sociedades pode ser percebida por meio da tradução quando o outro, o diferente, o estrangeiro é colocado à mostra.

90 A análise da tradução do texto em inglês neste artigo indica que a sociedade estadunidense prefere receber traduções sem informações que denunciem uma obra como uma tradução. Tanto as informações coletadas nos paratextos, como nos exemplos de tradução, sugerem que um texto domesticado é mais aceitável no âmbito das HQs.

Por outro lado, a tradução em português indica que o público leitor é mais receptivo à estrangeirização, pois o processo editorial e o nome do tradutor são colocados em destaque, assim como outras informações sobre a publicação em português. Os diálogos são gramaticalmente corretos. O texto não mimetiza os discursos orais, nem procura inserir muitas formas para atingir a oralidade fingida. Porém, a omissão de pronomes somente é feita a fim de não causar estranhamento pela repetição contínua desses.

Finalmente, pode-se observar nas comparações feitas neste artigo que as decisões de uma tradução pró-alvo ou etnocêntrica são explicitadas por meio de escolhas paratextuais, bem como escolhas linguísticas e culturais de acordo com a ideologia e história de tradução de cada país. 


\section{REFERÊNCIAS BIBLIOGRÁFICAS}

BERMAN, A tradução e a letra ou o albergue do longínquo. $2^{a}$ edição, Florianópolis, PGET/UFSC Copiart, 2012.

BRAGA, Ana Cláudia Viera. Norma linguística e oralidade fingida na tradução de Persépolis. Brasília, 2014. Dissertação de mestrado. (Mestrado em Estudos da Tradução) Universidade de Brasília, Brasília, 2014. Disponível em: <http://repositorio.unb.br/handle/10482/15091> Acesso online em 23 de dezembro de 2014.

ECO, Umberto. Apocalípticos e Integrados. São Paulo: Perspectiva (Debates, 19), 1979.

EISNER, Will. Quadrinhos e arte sequencial: princípios e práticas do lendário cartunista. Trad: BOIDE, Alexandre; BORGES, Luis Carlos. $2^{\mathrm{a}}$ tiragem. São Paulo: WMF Martins, 2012.

FERREIRA DE FREITAS, Luana; ARAÚJO DA SILVA, Camila. Autoria, paratexto e recepção das traduções de Venuti. Eutomia, edição 10, dez.2012, pp. 239-246.

GENETTE, Gérard; MACLEAN, Marta. Introduction to paratext. New Literary History, Vol. 22, No. 2, Probings: Art, Criticism, Genre. (Spring, 1991), pp.

261-272

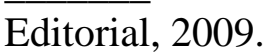

Paratextos editoriais. Trad: FALEIROS, Álvaro. Cotia, São Paulo: Ateliê

HERGÉ. Le lotus bleu. Belgium: Casterman, 1975.

O lótus azul. Trad: BRANDÃO, Eduardo. São Paulo: Quadrinhos na Cia, 2005.

The blue lotus. New York: Little, Brown and Company, 2011.

MCCLOUD, Scott. Desvendando os quadrinhos. São Paulo, M.Books, 2004.

OUSTINOFF, Michaël. Trad: MARCONILDO, Marcos. Tradução: História, teorias e métodos. São Paulo, Parábola Editorial, 2011.

RAMOS, Paulo. Faces do humor - uma aproximação entre piadas e tiras. São Paulo: Zarabatana Books. 2011.

A leitura dos quadrinhos. $2^{\mathrm{a}}$ edição. São Paulo: Editora Contexto, 2012.

Estratégias de referenciação emtextos multimodais: uma aplicação em tiras cômicas. Linguagem em (Dis)curso, Tubarão, SC, v. 12, n. 3, p. 743-763, set./dez. 2012.

ROSA, Gisele Marion. A tradução quadrinhística: sinais de conflito entre imagem e texto. In: Tradterm, 16, São Paulo, 2010, pp. 411-434.

SANTAELLA, Lúcia. Semiótica aplicada. São Paulo: Pioneira Thomson Learning, 2002. 
SERRA E DEUS, Lílian Paula. A língua é minha pátria: hibridação e expressão de identidades nas literaturas africanas de língua portuguesa. Belo Horizonte, 2012. Dissertação de mestrado. Pontifícia Universidade Católica de Minas Gerais, Programa de Pós-Graduação em Letras. Disponível em: <http://www.biblioteca.pucminas.br/teses/Letras_DeusLPS_1.pdf> Acesso online em 23 de novembro de 2014.

VENUTI, Lawrence. O escândalo da tradução. In: Tradterm 3, São Paulo, 1996. pp. 111-122.

The scandals of translation: toward an ethics of difference. New York: Routledge, 1998

RECEBIDO EM 29/12/2014

ACEITO EM 17/01/2015

${ }^{1}$ Lattes Gabriela $\quad$ C.T.N. do Nascimento: Disponível em: http://buscatextual.cnpq.br/buscatextual/visualizacv.do?id=K4831429Y7. Acesso: jan. 2015.

${ }^{2}$ De acordo com Oustinoff (2011, p.56), "Eugene E. Nida distingue duas formas de equivalência: a equivalência formal, que consiste em verter mecanicamente a forma do original; a equivalência dinâmica, que transforma o 'texto fonte' de maneira a produzir o mesmo efeito na 'língua-alvo"'.

${ }^{3}$ Name - http://en.tintin.com/personnages/show/id/16/page/0/0/snowy

${ }^{4}$ Editora Hachette, editora parceira da editora Little, Brown and Company http://www.hachettebookgroup.com/titles/herge/the-blue-lotus/9780316133821/ - acesso online em $22 \mathrm{de}$ dezembro de 2014. 